\title{
Transient Receptor Potential Channels and Botulinum Neurotoxins in Chronic Pain
}

\author{
Eun Jin Go ${ }^{1+}$, Jeongkyu Ji2t, Yong Ho Kim ${ }^{1}$, Temugin Berta ${ }^{3 *}$ and Chul-Kyu Park ${ }^{1 *}$ \\ ${ }^{1}$ Department of Physiology, Gachon Pain Center, Gachon University College of Medicine, Incheon, South Korea, ${ }^{2}$ Gachon \\ University College of Medicine, Incheon, South Korea, ${ }^{3}$ Department of Anesthesiology, Pain Research Center, University \\ of Cincinnati Medical Center, Cincinnati, OH, United States
}

\section{OPEN ACCESS}

Edited by:

Michaela Kress,

Innsbruck Medical University, Austria

Reviewed by:

Antonio Ferrer-Montiel,

Miguel Hernández University of Elche

Spain

Antti Pertovaara

University of Helsinki, Finland

*Correspondence:

Temugin Berta

temugin.berta@uc.edu

Chul-Kyu Park

pck0708@gachon.ac.kr

tThese authors have contributed equally to this work

Specialty section:

This article was submitted to Pain Mechanisms and Modulators,

a section of the journal

Frontiers in Molecular Neuroscience

Received: 08 September 2021 Accepted: 11 October 2021

Published: 29 October 2021

Citation:

Go EJ, Ji J, Kim YH, Berta T and Park C-K (2021) Transient Receptor Potential Channels and Botulinum

Neurotoxins in Chronic Pain.

Front. Mol. Neurosci. 14:772719. doi: 10.3389/fnmol.2021.772719
Pain afflicts more than 1.5 billion people worldwide, with hundreds of millions suffering from unrelieved chronic pain. Despite widespread recognition of the importance of developing better interventions for the relief of chronic pain, little is known about the mechanisms underlying this condition. However, transient receptor potential (TRP) ion channels in nociceptors have been shown to be essential players in the generation and progression of pain and have attracted the attention of several pharmaceutical companies as therapeutic targets. Unfortunately, TRP channel inhibitors have failed in clinical trials, at least in part due to their thermoregulatory function. Botulinum neurotoxins (BoNTs) have emerged as novel and safe pain therapeutics because of their regulation of exocytosis and pro-nociceptive neurotransmitters. However, it is becoming evident that BoNTs also regulate the expression and function of TRP channels, which may explain their analgesic effects. Here, we summarize the roles of TRP channels in pain, with a particular focus on TRPV1 and TRPA1, their regulation by BoNTs, and briefly discuss the use of BoNTs for the treatment of chronic pain.

\footnotetext{
Keywords: chronic pain, migraine, TRPV1, TRPA1, exocytosis, botulinum neurotoxin
}

\section{INTRODUCTION}

Pain is defined as an unpleasant sensory and emotional experience associated with or resembling that associated with actual or potential tissue damage (Kuner, 2010). Acute pain is transient and beneficial and mainly functions as a protective warning for the body. In contrast, chronic pain is a persistent and debilitating condition for which there are few treatment options (Treede et al., 2015). Chronic pain manifests in symptoms such as spontaneous pain, hyperalgesia (i.e., increased pain from a stimulus that normally provokes pain), and allodynia (i.e., pain due to a stimulus that does not normally provoke pain) (Treede et al., 1992). Chronic pain has numerous etiologies, including arthritis-induced inflammatory pain, cancer pain, diabetic neuropathy, spinal cord injury, and nerve injury. Although pain results from the complex processing of neural signals at different levels of the nervous system (Costigan et al., 2009; Reichling and Levine, 2009), targeting the beginning of the pain pathway and aim potential treatments directly at receptors and ion channels expressed in nociceptors (i.e., peripheral sensory neurons that detect pain) seems to be a logical strategy for developing novel analgesics.

Among all the receptors and ion channels expressed in nociceptors, transient receptor potential (TRP) ion channels have been extensively studied for their participation in various acute and chronic pain conditions (Lumpkin and Caterina, 2007), with TRPV1 and TRPA1 having emerged as especially promising targets for analgesics. Both TRPV1 and TRPA1 act as polymodal detectors in 
nociceptors, and their activation by endogenous mediators and natural products (e.g., capsaicin and mustard oil, respectively) can elicit pain (Scholz and Woolf, 2002; Jardin et al., 2017). Further proof of the involvement of these ion channels in pain is provided by their well-reported transcriptional, translational, and trafficking regulation, leading to nociceptor hyperexcitability and pain after inflammation or nerve injury (Hucho and Levine, 2007). For these reasons, several pharmaceutical companies have been conducting clinical trials of TRPV1 and TRPA1 antagonists. However, these antagonists, mainly those of TRPV1, have demonstrated undesirable adverse side effects such as hyperthermia (Gavva et al., 2008), reduced heat pain threshold, and reduced taste perception (Patapoutian et al., 2009). These findings suggest that additional strategies should be pursued to target TRP channels and alleviate pain.

Botulinum neurotoxins (BoNTs) have demonstrated analgesic effects in various animal models of acute and chronic pain, and the use of BoNT serotype-A (BoNT/A) is currently approved for the treatment of chronic migraines (Matak et al., 2019). However, knowledge of the mechanisms by which BoNTs inhibit pain is currently limited. Although it has been suggested that such inhibition is driven by the modulation of pro-nociceptive neuropeptides, BoNTs have been shown to interact with and regulate TRP channels, which may underlie their analgesic effects.

In this succinct review, we focus on TRPV1 and TRPA1 as essential nociceptive mediators, present the underlying mechanisms of their interaction and regulation by BoNTs, and finally propose BoNTs as a novel strategy to treat various acute and chronic pain conditions.

\section{TRANSIENT RECEPTOR POTENTIAL CHANNELS IN CHRONIC PAIN}

TRP channels are non-selective ion channels mostly located on the plasma membrane of various cell types and are divided into six main groups: TRPV (vanilloid), TRPA (ankyrin), TRPM (melastatin), TRPC (canonical), TRPP (polycystin), and TRPML (mucolipin) (Chung and Caterina, 2007). The first suggestion that TRP channels were key receptors involved in sensory transduction emerged from the identification of TRPV1 as a capsaicin- and heat-activated ion channel (Rosenbaum and Simon, 2007). Cutaneous injection of capsaicin, the active ingredient of chili peppers, induces pain-like sensations such as burning, itching, piercing, pricking, and stinging ( $\mathrm{O}^{\prime} \mathrm{Neill}$ et al., 2012). Similarly, several pungent chemicals (e.g., mustard and cinnamon, but not capsaicin) activate TRPA1, which can also lead to pain-like sensations (Patapoutian et al., 2009). TRP channels can participate in acute and chronic pain through transcriptional and translational regulation, post-translational changes, and altered trafficking (Patapoutian et al., 2009). Among neurons, nociceptors uniquely express TRPV1 and TRPA1, which make them particularly interesting in the chronic pain states, since their expression and function after inflammation and nerve injury contribute to the pathological pain states by increasing sensitivity to nociceptive stimuli (i.e., peripheral sensitization) (Hucho and Levine, 2007).
During inflammation, both TRPV1 and TRPA1 transcripts are increased through the neuronal C-C chemokine receptor type 2 (CCR2), which is activated by the release, by macrophages, of pro-inflammatory protein-1 $\alpha$ (MIP-1 $\alpha /$ CCL3) (Jung et al., 2008). Similarly, oxidative stress products generated by tissue damage and inflammation lead to increased expression and function of TRP channels, resulting in neuronal hyperexcitability and pain (Hucho and Levine, 2007). It has also been shown that pro-inflammatory mediators such as tumor necrosis factor (TNF)- $\alpha$ engage both the PKC and PKA signaling pathways, altering the activity and function of TRPV1 (Premkumar and Ahern, 2000; Chuang et al., 2001; Vellani et al., 2001; Bhave et al., 2002, 2003; Crandall et al., 2002; Numazaki et al., 2002, 2003; Prescott and Julius, 2003), whereas nerve growth factor (NGF), acting via p38 mitogenactivated protein kinases (MAPKs), increases the translation of TRPV1 in the cell body, and promotes its trafficking to the peripheral terminals (Ji et al., 2002). In addition to the complexity of TRP channels, their trafficking to the cellular membrane is followed by further activation of second-messenger pathways and post-translational modifications such as channel phosphorylation and glycosylation (Morenilla-Palao et al., 2004; Zhang et al., 2005).

Nerve injury also leads to regulation of TRP channels. Although the expression and function of TRPV1 are altered after spinal nerve ligation, with decreased TRPV1 expression in injured neurons likely due to trophic support (Michael and Priestley, 1999), increases in TRPV1 and TRPA1 expression in neighboring non-injured neurons are accompanied by hyperalgesia and allodynia (Hudson et al., 2001; Obata et al., 2005). It has been suggested that the increase in TRP channel expression in non-injured neurons is driven by the release of neuropeptides, growth factors, and pro-inflammatory mediators from injured neurons (Fukuoka et al., 2001; Sexton et al., 2014). Indeed, TNF$\alpha$ alone has been shown to increase the fraction of dorsal root ganglion (DRG) neurons expressing TRPV1 (Hensellek et al., 2007). Likewise, a study reported TRPV1 and TRPA1 trafficking in calcitonin gene-related peptide (CGRP)-releasing vesicles, induced by TNF- $\alpha$ via membrane fusion mediated by soluble N-ethylmaleimide-sensitive factor attachment protein receptors (SNAREs) in trigeminal ganglion neurons (Meng et al., 2016).

Although TRP channels convert thermal, chemical, and noxious stimuli into electrical activity on the peripheral terminals of sensory neurons, they are also found on the synapses in the central terminals of nociceptors projecting into the dorsal horn of the spinal cord (Patapoutian et al., 2009). Interestingly, activation of synaptic TRPV1 and TRPA1 by intrathecal injections of capsaicin and mustard oil, respectively, results in an increase in synaptic release of both glutamate and neuropeptides (Raisinghani et al., 2011). Increased expression of TRPV1 in synaptic terminals after nerve injury leads to increased release of inflammatory neuropeptides such as CGRP and substance P (SP), which also enhance glutamatergic neurotransmission and pain (Kanai et al., 2005; Lappin et al., 2006; Lee and Kim, 2007; Spicarova et al., 2011). 
These results suggest a possible role of TRP channel inhibitors, similar to that of BoNTs, as synaptic modulators, by which they can reduce depolarization and control calcium influx and synaptic vesicle exocytosis. Unfortunately, direct inhibition of TRP channels, such as TRPV1, is associated with thermoregulation and adverse side effects. However, targeting the synaptic function of TRP channels and exocytosis may offer a novel and safer therapeutic approach to treat acute and chronic pain.

\section{BOTULINUM NEUROTOXIN: INHIBITION OF EXOCYTOSIS}

BoNTs are among the most potent biological toxins produced by neurotoxigenic strains of anaerobic and spore-forming bacteria of the genus Clostridium (Mohanty et al., 2001). However, local injection of a small amount of BoNTs is safe and has a wide spectrum of applications for both therapeutic and cosmetic indications (Truong et al., 2009; Dressler, 2012). BoNTs have been traditionally classified into seven serotypes distinguishable with animal antisera and designated with the letters A to G, among which BoNT/A is a commercially available human indication (Simpson, 1981). BoNTs are typical AB-structured toxins, consisting of a heavy chain with membrane acceptorbinding and translocation domains, and a smaller light chain with a catalytic domain that mediates the cytosolic proteolytic activity of these neurotoxins.

The basis of BoNT therapeutic indications is the neuronal inhibition of exocytosis, as they are known for their cleavage of synaptic components of the SNARE complex proteins, thus blocking the release of neurotransmitters, such as CGRP, SP, and glutamate (Nakov et al., 1989; McMahon et al., 1992; Pirazzini et al., 2017). The inhibition of exocytosis by botulinum toxin involves three steps: binding, internalization/translocation, and cleavage of the target (Schiavo et al., 2000). Neuronal tropism is due to a high-affinity interaction of the BoNT heavy chain with double acceptors consisting of gangliosides and synaptic vesicle 2 (SV2A-C) protein isoforms expressed on the extracellular side of the neuronal membrane (Muraro et al., 2009). Internalization of BoNTs occurs via endocytosis, and in the endosome the light chain dissociates from the heavy chain by reduction of the disulfide bridge, being then released into the cytoplasm by an energy- and $\mathrm{pH}$-dependent pore-forming process (Pirazzini et al., 2017). In the cytoplasm, the BoNT light chain cleaves one of the proteins that make up the SNARE complex: synaptobrevin or vesicle-associated membrane proteins (VAMPs), syntaxin-1, and synaptosomal-associated protein 25 (SNAP-25) (Sudhof and Rothman, 2009). This cleavage is highly specific to each BoNT serotype and directed toward unique peptide bonds within the sequence of their respective SNARE protein targets (Pirazzini et al., 2017); for instance, it has been reported that BoNT/A cleaves 9 amino acids at the C-terminus of SNAP-25 (Lebeda et al., 2010). This cleavage results in reduced affinity of the intracellular $\mathrm{Ca}^{2+}$ sensor synaptotagmin to SNAP-25, thus impairing exocytosis and the synaptic release of neurotransmitters (Tang et al., 2006; Pan et al., 2009), which, in our context, propagate pain.
Although inhibition of exocytosis and prevention of neurotransmitter release are fundamental mechanisms underlying the neuronal effects of BoNTs, new mechanisms are emerging to explain the specific and potent analgesic effects of these toxins, including their interactions with and regulation of TRP channels.

\section{BOTULINUM NEUROTOXIN: INHIBITION OF TRP CHANNELS}

Sensory information is not equally affected by BoNTs, and it has been reported that BoNT/A mostly alleviates pathological inflammatory pain and mechanical sensation (Cui et al., 2004; Bach-Rojecky et al., 2005; Luvisetto et al., 2006, 2007; Park et al., 2006). This suggests distinct neuronal tropisms for specific sensory neurons. It is also possible that BoNT/A may favor particular sensory neurons with high expression of SV2 proteins that facilitate its entry (Yiangou et al., 2011). Yet another interesting hypothesis stems from the observation that BoNT/A interacts with TRPV1 both structurally and functionally (Li and Coffield, 2016), and therefore selectively enters TRPV1-expressing sensory neurons. Indeed, it has been reported that SNAP-25 cleavage and the analgesic effects of BoNT/A were prevented in animals following denervation of TRPV1-expressing sensory neurons achieved with high doses of capsaicin, an agonist of TRPV1 (Apostolidis et al., 2005; Camprubi-Robles et al., 2009; Shimizu et al., 2012). In line with this preclinical observation, neuropathic pain patients with lower thermal deficits, and thus presumably with lower impairment of TRPV1-expressing sensory neurons, responded better to BoNT/A treatment (Attal et al., 2016).

BoNTs reduce the expression of TRP channels in sensory neurons (Figure 1). It has been reported that BoNT/A treatment decreases TRPV 1 expression in sensory neurons projecting from the dura mater (Shimizu et al., 2012) and significantly reduces the overexpression of injury-induced TRPV1 protein, but not mRNA, in sensory neurons of the DRG (Xiao et al., 2013). It has been proposed that BoNT/A might block the translocation of TRPV 1 to the sensory neurons, as reduced surface expression of the TRPV1 protein was observed in vivo and in vitro (Gazerani et al., 2006; Tugnoli et al., 2007; Meng et al., 2009; Wang et al., 2011). Another in vitro study using a recombinant chimera of BoNT/A and BoNT/E also showed a decrease in TNF- $\alpha$-dependent TRPV1 and TRPA1 protein translocation to the cellular membrane of sensory neurons (Wang et al., 2017; Nugent et al., 2018).

BoNTs may interfere with TRP channel protein translocation by cleavage of SNAP-25, impairing both synaptic $\mathrm{Ca}^{2+}$ concentration and exocytosis (Meng et al., 2009; Meng et al., 2014). Cleavage of SNARE proteins by BoNTs has been demonstrated in sensory neurons. In particular, BoNT/A has been reported to impair exocytosis and recruitment of the TRPV1 receptor to the plasma membrane of nociceptors after stimulation with capsaicin (Gazerani et al., 2006; Gazerani et al., 2009) or mustard oil (Paterson et al., 2014). TRPA1 contributes to mechanical currents in the plasma membrane, and it has been proposed that BoNT/A may also decrease the activity 


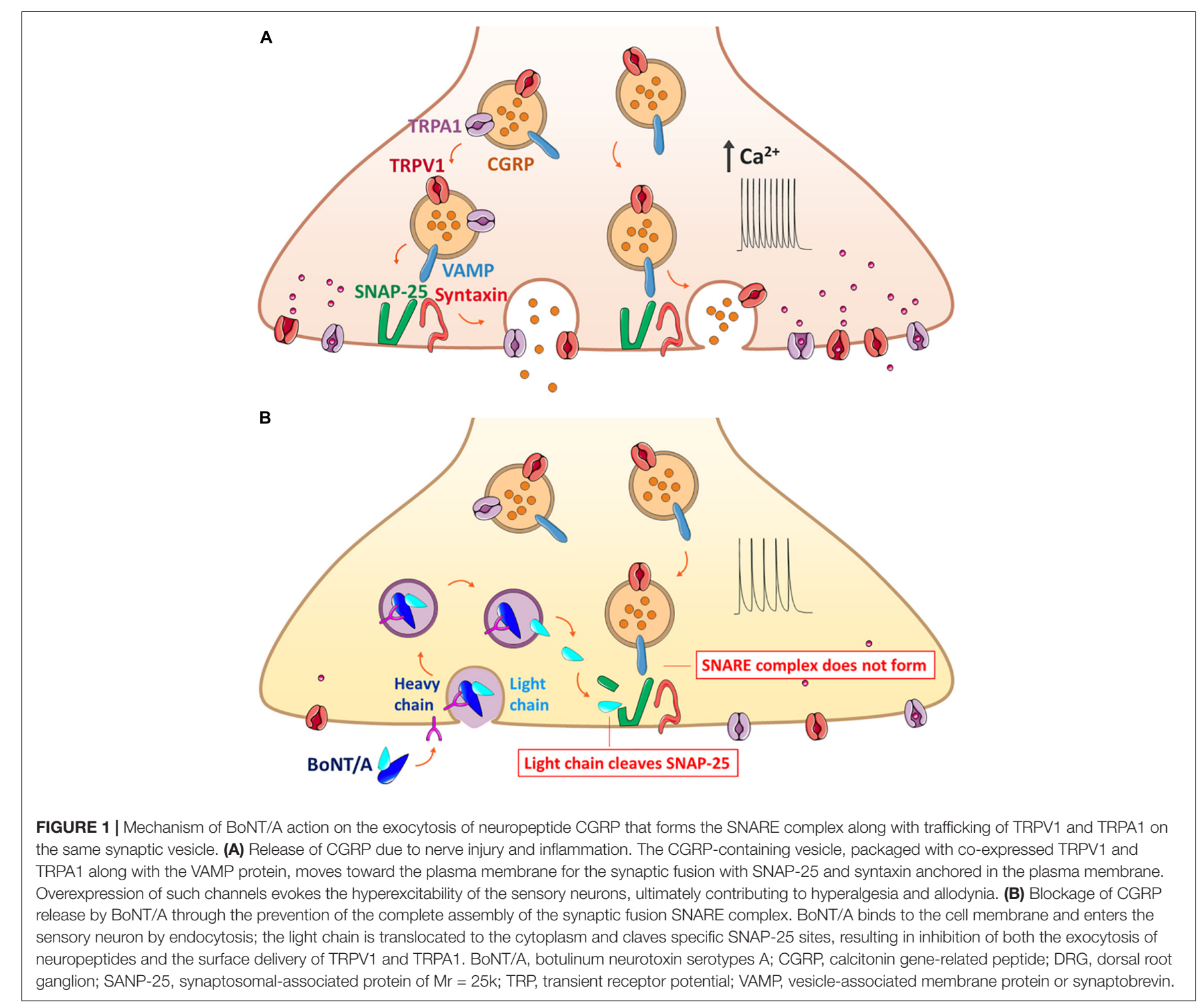

of mechanosensitive receptors and TRPA1 in dural afferents (Burstein et al., 2014; Paterson et al., 2014).

Altogether, these studies demonstrated that BoNTs have distinct tropism toward TRPV1-expressing sensory neurons and can lead to decreased expression and translocation of TRP channels, resulting in a reduction in synaptic $\mathrm{Ca}^{2+}$ concentration, release of neurotransmitters, and alleviation of pain. Table 1 shows a list of published studies in which the analgesic effect of BoNT is achieved via modulation of TRP channels in various types of pain.

\section{BOTULINUM NEUROTOXIN: PAIN TREATMENT}

Botulinum toxin treatments have been demonstrated to be effective and are currently used for the treatment of chronic migraine, while clinical trials are ongoing for their use in other pain conditions (Burstein et al., 2014). The efficiency and potency of these treatments can be due to BoNT multiple actions in nociceptors, modulation of TRP channels, and synaptic transmission. BoNT/A has shown analgesic effects in both acute and chronic animal models of pain. However, such analgesic effects are still debatable, and this toxin cannot attenuate the spinal release of neuropeptides and the pain induced by injection of a high dose of capsaicin. This is probably due to the limited cleavage of SNAP-25 by BoNT/A, which fails to prevent the formation of a functional SNARE complex (Meng et al., 2009, 2014).

To improve the functional and analgesic effects of BoNTs, researchers have started to study additional BoNT serotypes and transgenic chimeras. In particular, BoNT/E cleaves 26 residues from SNAP-25 (compared with nine cleaved by BoNT/A) and may better prevent the formation of the SNARE complex (Meng et al., 2009; Wang et al., 2011). However, 
TABLE 1 | Analgesic effects of BoNTs through TRP channels in various types of pain.

\begin{tabular}{|c|c|c|c|c|c|c|}
\hline References & $\begin{array}{l}\text { BoNT } \\
\text { serotype }\end{array}$ & $\begin{array}{l}\text { Administration } \\
\text { site/Doses }\end{array}$ & Pain type & $\begin{array}{l}\text { TRP } \\
\text { channel }\end{array}$ & $\begin{array}{l}\text { Action } \\
\text { duration }\end{array}$ & Results \\
\hline $\begin{array}{l}\text { Shimizu et al. } \\
\text { (2012) }\end{array}$ & BoNT/A & $\begin{array}{l}\text { Subcutaneous }(0.25-5 \\
\mathrm{ng} / \mathrm{kg}) \text { in rat } \mathrm{TGN}\end{array}$ & $\begin{array}{l}\text { Nociceptive } \\
\text { pain }\end{array}$ & TRPV1 & 2-14 days & $\begin{array}{l}\text { - SNAP-25 cleavage } \\
\text { - } \downarrow \text { TRPV1 protein expression } \\
\text { - } \downarrow \text { Nociceptive behaviors } \\
\text { - Blockage of TRPV1 trafficking }\end{array}$ \\
\hline $\begin{array}{l}\text { Xiao et al. } \\
(2013)\end{array}$ & BoNT/A & $\begin{array}{l}\text { Intraplantar (10 or } 20 \mathrm{U} / \mathrm{kg} \text { ) } \\
\text { in rat }\end{array}$ & $\begin{array}{l}\text { Neuropathic } \\
\text { pain (L5 VRT) }\end{array}$ & TRPV1 & 3-21 days & $\begin{array}{l}\text { - Reversed hyperalgesia } \\
\text { - } \downarrow \text { TRPV1 overexpression }\end{array}$ \\
\hline $\begin{array}{l}\text { Luvisetto et al. } \\
\text { (2015) }\end{array}$ & BoNT/A & $\begin{array}{l}\text { Subcutaneous in the inner } \\
\text { side of the medial part of } \\
\text { hindlimb thigh ( } 15 \mathrm{pg}) \text { of } \\
\text { mice }{ }^{\star *} \text { pre-treated }\end{array}$ & $\begin{array}{l}\text { Nociceptive } \\
\text { pain }\end{array}$ & $\begin{array}{l}\text { TRPV1 } \\
\text { TRPA1 }\end{array}$ & 21 days & - $\downarrow$ Nociceptive behaviors \\
\hline $\begin{array}{l}\text { Fan et al. } \\
(2017)\end{array}$ & BoNT/A & $\begin{array}{l}\text { Percutaneous in tibial-tarsal } \\
\text { hind joint }(2.5-25 \mathrm{U} / \mathrm{kg}) \text { of } \\
\text { rats }\end{array}$ & $\begin{array}{l}\text { Adjuvant- } \\
\text { arthritis } \\
\text { pain }\end{array}$ & $\begin{array}{l}\text { TRPV1 } \\
\text { TRPA1 }\end{array}$ & 3-14 days & $\begin{array}{l}\text { - } \downarrow \text { mechanical allodynia and thermal } \\
\text { hyperalgesia } \\
-\downarrow \text { Protein levels of TRPV1 in DRG } \\
-\downarrow \text { TRPV1 expression in DRG } \\
-\downarrow \text { Percentage of TRPV1-positive neurons with } \\
\text { CGRP }\end{array}$ \\
\hline \multirow[t]{2}{*}{$\begin{array}{l}\text { Wang et al. } \\
\text { (2017) and } \\
\text { Nugent et al. } \\
\text { (2018) }\end{array}$} & LC/E-BoNT/A & $\begin{array}{l}\text { Intraplantar }(25-75 \mathrm{U} / \mathrm{Kg}) \text { in } \\
\text { rat }\end{array}$ & $\begin{array}{l}\text { Neuropathic } \\
\text { pain (SNI) }\end{array}$ & & 14 days & $\begin{array}{l}\text { - Blockage of CAP-evoked CGRP release } \\
\text { - Greater analgesic effect than BoNT/A or } \\
\text { pregabalin (short-acting pain modulator) } \\
\text { - Sustained and prolonged effect by a second } \\
\text { injection }\end{array}$ \\
\hline & & & & $\begin{array}{l}\text { TRPV1 } \\
\text { TRPA1 }\end{array}$ & & $\begin{array}{l}\text { - } \downarrow \text { Functional activities in TRPV1/A1 with no } \\
\text { basal surface contents of rat DRG } \\
\text { - } \downarrow \text { TNF- } \alpha \text {-dependent surface trafficking of } \\
\text { TRPV1/A1 and calcium influx in rat DRG }\end{array}$ \\
\hline
\end{tabular}

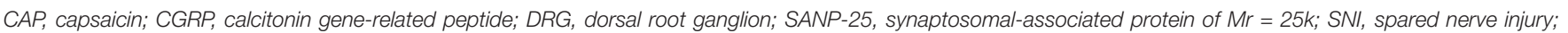
TGN, trigeminal neuron; TNF- $\alpha$, tumor necrosis factor- $\alpha$; TRP, transient receptor potential; VRT, ventral root transection. ** indicates supplementary information.

BoNT/E has a shorter half-life than BoNT/A (Wang et al., 2017). Therefore, researchers have generated a recombinant chimera of BoNT/A and BoNT/E which has shown analgesic effects for both mechanical and cold hypersensitivity in a spared nerve injury animal model of neuropathic pain, which is particularly refractory to current pain drugs. Indeed, a single injection of this chimera demonstrated long-lasting analgesic effects (up to 2 weeks) that were far superior to those of multiple injections of BoNT/A or pregabalin (Wang et al., 2017).

Despite these promising data, there are still challenges to be considered for the use of BoNTs in chronic pain. Some reports indicated the potential generation of antigens against BoNTs, which may explain the non-responsiveness to BoNTs in a handful of patients (Zuber et al., 1993; Stephan et al., 2014). Antigen generation may be reduced by developing novel BoNT formulations using alternative serotypes or different formulations (i.e., reducing protein load including adjuvants), or by minimizing exposure (i.e., increasing injection intervals and decreasing doses) (Bellows and Jankovic, 2019).

Several alternative serotypes are currently being explored, with BoNT/C appearing to be a promising substitute for BoNT/A, with similar efficacy and duration of action and, most importantly, demonstrated analgesic efficiency in BoNT/A-resistant patients (Eleopra et al., 1997, 2006). Similarly, BoNT/F showed positive results, although with shorter duration, in BoNT/A-resistant patients (Greene and Fahn, 1993). Different formulations are being tested, and Allergan Inc. developed a new BoNT/A formulation (Botox) containing less neurotoxin complex protein per unit, which was reported to generate fewer antigens in patients injected with the new formulation when compared with those injected with older ones (Jankovic et al., 2003).

BoNT treatment requires multiple cutaneous injections producing discomfort in patients that may require anesthesia (Kranz et al., 2006; Weiss and Lavin, 2009), as well as potential extravasation in blood vessels (Naumann and Jankovic, 2004; Roche et al., 2008) and undesired adverse effects such as hematoma, bruising, or muscular weakness, highlighting the importance of developing alternative delivery methods (Wyndaele and Van Dromme, 2002; Wollina and Konrad, 2005). Novel and diverse delivery methods are under robust investigation, including physical approaches such as transdermal and transepithelial delivery, chemical approaches for recruiting enhancers to increase permeability, or the use of liposomes, together with the previously mentioned method of creating recombinant forms for more precise delivery to target organs (Fonfria et al., 2018).

\section{CONCLUSION}

Chronic pain is a debilitating condition with few treatment options. Since their identification in nociceptors, interest in the role of TRP channels in pain and as therapeutic targets has steadily increased. Small-molecule inhibitors directly targeting TRPV1 and TRPA1 have been tested in various clinical trials 
without success, due to adverse side effects. Here, we summarized how TRP channel expression and function can be indirectly modulated by BoNTs, which are regarded as effective and safe analgesics. In particular, BoNT/A has been demonstrated to change the expression and translocation of TRP channels in nociceptors, and its analgesic effects have been proven experimentally in different acute and chronic pain conditions, as well as in the clinical treatment of chronic migraine. We believe that the continuous improvement of BoNTs and a better understanding of their mechanisms of action, including those involving the regulation of TRP channels, will lead to the clinical treatment of additional chronic pain conditions.

\section{REFERENCES}

Apostolidis, A., Popat, R., Yiangou, Y., Cockayne, D., Ford, A. P., Davis, J. B., et al. (2005). Decreased sensory receptors P2X3 and TRPV1 in suburothelial nerve fibers following intradetrusor injections of botulinum toxin for human detrusor overactivity. J. Urol. 174, 977-982. doi: 10.1097/01.ju.0000169481.42259.54 discussion 982-973,

Attal, N., de Andrade, D. C., Adam, F., Ranoux, D., Teixeira, M. J., Galhardoni, R., et al. (2016). Safety and efficacy of repeated injections of botulinum toxin A in peripheral neuropathic pain (BOTNEP): a randomised, doubleblind, placebo-controlled trial. Lancet Neurol. 15, 555-565. doi: 10.1016/S14744422(16)00017-X

Bach-Rojecky, L., Relja, M., and Lackovic, Z. (2005). Botulinum toxin type A in experimental neuropathic pain. J. Neural Transm. (Vienna) 112, 215-219. doi: 10.1007/s00702-004-0265-1

Bellows, S., and Jankovic, J. (2019). Immunogenicity associated with botulinum toxin treatment. Toxins (Basel) 11:491. doi: 10.3390/toxins11090491

Bhave, G., Hu, H. J., Glauner, K. S., Zhu, W., Wang, H., Brasier, D. J., et al. (2003). Protein kinase $\mathrm{C}$ phosphorylation sensitizes but does not activate the capsaicin receptor transient receptor potential vanilloid 1 (TRPV1). Proc. Natl. Acad. Sci. U. S. A. 100, 12480-12485. doi: 10.1073/pnas.2032100100

Bhave, G., Zhu, W., Wang, H., Brasier, D. J., Oxford, G. S., and Gereau, R. W. IV (2002). cAMP-dependent protein kinase regulates desensitization of the capsaicin receptor (VR1) by direct phosphorylation. Neuron 35, 721-731. doi: 10.1016/s0896-6273(02)00802-4

Burstein, R., Zhang, X., Levy, D., Aoki, K. R., and Brin, M. F. (2014). Selective inhibition of meningeal nociceptors by botulinum neurotoxin type A: therapeutic implications for migraine and other pains. Cephalalgia 34, 853-869. doi: $10.1177 / 0333102414527648$

Camprubi-Robles, M., Planells-Cases, R., and Ferrer-Montiel, A. (2009). Differential contribution of SNARE-dependent exocytosis to inflammatory potentiation of TRPV1 in nociceptors. FASEB J. 23, 3722-3733. doi: 10.1096/ fj.09-134346

Chuang, H. H., Prescott, E. D., Kong, H., Shields, S., Jordt, S. E., Basbaum, A. I., et al. (2001). Bradykinin and nerve growth factor release the capsaicin receptor from PtdIns(4,5)P2-mediated inhibition. Nature 411, 957-962. doi: 10.1038/ 35082088

Chung, M. K., and Caterina, M. J. (2007). TRP channel knockout mice lose their cool. Neuron 54, 345-347. doi: 10.1016/j.neuron.2007.04.025

Costigan, M., Scholz, J., and Woolf, C. J. (2009). Neuropathic pain: a maladaptive response of the nervous system to damage. Annu. Rev. Neurosci. 32, 1-32. doi: 10.1146/annurev.neuro.051508.135531

Crandall, M., Kwash, J., Yu, W., and White, G. (2002). Activation of protein kinase $\mathrm{C}$ sensitizes human VR1 to capsaicin and to moderate decreases in $\mathrm{pH}$ at physiological temperatures in Xenopus oocytes. Pain 98, 109-117. doi: 10.1016/s0304-3959(02)00034-9

Cui, M., Khanijou, S., Rubino, J., and Aoki, K. R. (2004). Subcutaneous administration of botulinum toxin A reduces formalin-induced pain. Pain 107, 125-133. doi: 10.1016/j.pain.2003.10.008

Dressler, D. (2012). Clinical applications of botulinum toxin. Curr. Opin. Microbiol. 15, 325-336. doi: 10.1016/j.mib.2012.05.012

\section{AUTHOR CONTRIBUTIONS}

$\mathrm{C}-\mathrm{KP}$ and TB conceived and supervised the project. EJG, JJ, YHK, and $\mathrm{C}-\mathrm{KP}$ wrote the manuscript. All authors contributed to the article and approved the submitted version.

\section{FUNDING}

This work was supported by grants from the National Research Foundation of Korea (NRF- 2017M3C7A1025602 to YHK) and the US National Health Institute (NS121946 and NS113243 to TB).

Eleopra, R., Tugnoli, V., Quatrale, R., Rossetto, O., Montecucco, C., and Dressler, D. (2006). Clinical use of non-A botulinum toxins: botulinum toxin type $C$ and botulinum toxin type F. Neurotoxicity Res. 9, 127-131.

Eleopra, R., Tugnoli, V., Rossetto, O., Montecucco, C., and De Grandis, D. (1997). Botulinum neurotoxin serotype C: a novel effective botulinum toxin therapy in human. Neurosci. Lett. 224, 91-94. doi: 10.1016/s0304-3940(97)13448-6

Fan, C., Chu, X., Wang, L., Shi, H., and Li, T. (2017). Botulinum toxin type A reduces TRPV1 expression in the dorsal root ganglion in rats with adjuvantarthritis pain. Toxicon 133, 116-122. doi: 10.1016/j.toxicon.2017.05.001

Fonfria, E., Maignel, J., Lezmi, S., Martin, V., Splevins, A., Shubber, S., et al. (2018). The expanding therapeutic utility of botulinum neurotoxins. Toxins (Basel) 10:208. doi: 10.3390/toxins 10050208

Fukuoka, T., Kondo, E., Dai, Y., Hashimoto, N., and Noguchi, K. (2001). Brainderived neurotrophic factor increases in the uninjured dorsal root ganglion neurons in selective spinal nerve ligation model. J. Neurosci. 21, 4891-4900.

Gavva, N. R., Treanor, J. J., Garami, A., Fang, L., Surapaneni, S., Akrami, A., et al. (2008). Pharmacological blockade of the vanilloid receptor TRPV1 elicits marked hyperthermia in humans. Pain 136, 202-210. doi: 10.1016/j.pain.2008. 01.024

Gazerani, P., Pedersen, N. S., Staahl, C., Drewes, A. M., and Arendt-Nielsen, L. (2009). Subcutaneous botulinum toxin type A reduces capsaicin-induced trigeminal pain and vasomotor reactions in human skin. Pain 141, 60-69. doi: 10.1016/j.pain.2008.10.005

Gazerani, P., Staahl, C., Drewes, A. M., and Arendt-Nielsen, L. (2006). The effects of botulinum toxin type A on capsaicin-evoked pain, flare, and secondary hyperalgesia in an experimental human model of trigeminal sensitization. Pain 122, 315-325. doi: 10.1016/j.pain.2006.04.014

Greene, P. E., and Fahn, S. (1993). Use of botulinum toxin type F injections to treat torticollis in patients with immunity to botulinum toxin type A. Mov. Disord. 8, 479-483. doi: 10.1002/mds.870080411

Hensellek, S., Brell, P., Schaible, H. G., Brauer, R., and Segond von Banchet, G. (2007). The cytokine TNFalpha increases the proportion of DRG neurones expressing the TRPV1 receptor via the TNFR1 receptor and ERK activation. Mol. Cell Neurosci. 36, 381-391. doi: 10.1016/j.mcn.2007.07.010

Hucho, T., and Levine, J. D. (2007). Signaling pathways in sensitization: toward a nociceptor cell biology. Neuron 55, 365-376. doi: 10.1016/j.neuron.2007. 07.008

Hudson, L. J., Bevan, S., Wotherspoon, G., Gentry, C., Fox, A., and Winter, J. (2001). VR1 protein expression increases in undamaged DRG neurons after partial nerve injury. Eur. J. Neurosci. 13, 2105-2114. doi: 10.1046/j.0953-816x. 2001.01591.x

Jankovic, J., Vuong, K. D., and Ahsan, J. (2003). Comparison of efficacy and immunogenicity of original versus current botulinum toxin in cervical dystonia. Neurology 60, 1186-1188. doi: 10.1212/01.wnl.0000055087.96356.bb

Jardin, I., Lopez, J. J., Diez, R., Sanchez-Collado, J., Cantonero, C., Albarran, L., et al. (2017). TRPs in pain sensation. Front. Physiol. 8:392. doi: 10.3389/fphys. 2017.00392

Ji, R. R., Samad, T. A., Jin, S. X., Schmoll, R., and Woolf, C. J. (2002). p38 MAPK activation by NGF in primary sensory neurons after inflammation increases TRPV1 levels and maintains heat hyperalgesia. Neuron 36, 57-68. doi: 10.1016/ s0896-6273(02)00908-x 
Jung, H., Toth, P. T., White, F. A., and Miller, R. J. (2008). Monocyte chemoattractant protein-1 functions as a neuromodulator in dorsal root ganglia neurons. J. Neurochem. 104, 254-263. doi: 10.1111/j.1471-4159.2007.04969.x

Kanai, Y., Nakazato, E., Fujiuchi, A., Hara, T., and Imai, A. (2005). Involvement of an increased spinal TRPV1 sensitization through its up-regulation in mechanical allodynia of CCI rats. Neuropharmacology 49, 977-984. doi: 10. 1016/j.neuropharm.2005.05.003

Kranz, G., Sycha, T., Voller, B., Gleiss, A., Schnider, P., and Auff, E. (2006). Pain sensation during intradermal injections of three different botulinum toxin preparations in different doses and dilutions. Dermatol. Surg. 32, 886-890. doi: $10.1111 / j .1524-4725.2006 .32191 . x$

Kuner, R. (2010). Central mechanisms of pathological pain. Nat. Med. 16, 12581266. doi: $10.1038 / \mathrm{nm} .2231$

Lappin, S. C., Randall, A. D., Gunthorpe, M. J., and Morisset, V. (2006). TRPV1 antagonist, SB-366791, inhibits glutamatergic synaptic transmission in rat spinal dorsal horn following peripheral inflammation. Eur. J. Pharmacol. 540, 73-81. doi: 10.1016/j.ejphar.2006.04.046

Lebeda, F. J., Cer, R. Z., Mudunuri, U., Stephens, R., Singh, B. R., and Adler, M. (2010). The zinc-dependent protease activity of the botulinum neurotoxins. Toxins (Basel) 2, 978-997. doi: 10.3390/toxins2050978

Lee, S. E., and Kim, J. H. (2007). Involvement of substance P and calcitonin generelated peptide in development and maintenance of neuropathic pain from spinal nerve injury model of rat. Neurosci. Res. 58, 245-249. doi: 10.1016/j. neures.2007.03.004

Li, X., and Coffield, J. A. (2016). Structural and functional interactions between transient receptor potential vanilloid subfamily 1 and Botulinum neurotoxin serotype A. PLoS One 11:e0143024. doi: 10.1371/journal.pone.0143024

Lumpkin, E. A., and Caterina, M. J. (2007). Mechanisms of sensory transduction in the skin. Nature 445, 858-865. doi: 10.1038/nature05662

Luvisetto, S., Marinelli, S., Cobianchi, S., and Pavone, F. (2007). Anti-allodynic efficacy of botulinum neurotoxin $\mathrm{A}$ in a model of neuropathic pain. Neuroscience 145, 1-4. doi: 10.1016/j.neuroscience.2006.12.004

Luvisetto, S., Marinelli, S., Lucchetti, F., Marchi, F., Cobianchi, S., Rossetto, O., et al. (2006). Botulinum neurotoxins and formalin-induced pain: central vs. peripheral effects in mice. Brain Res. 1082, 124-131. doi: 10.1016/j.brainres. 2006.01.117

Luvisetto, S., Vacca, V., and Cianchetti, C. (2015). Analgesic effects of botulinum neurotoxin type A in a model of allyl isothiocyanate- and capsaicin-induced pain in mice. Toxicon 94, 23-28. doi: 10.1016/j.toxicon.2014.12.007

Matak, I., Bolcskei, K., Bach-Rojecky, L., and Helyes, Z. (2019). Mechanisms of botulinum toxin type A action on pain. Toxins (Basel) 11:459.

McMahon, H. T., Foran, P., Dolly, J. O., Verhage, M., Wiegant, V. M., and Nicholls, D. G. (1992). Tetanus toxin and botulinum toxins type A and B inhibit glutamate, gamma-aminobutyric acid, aspartate, and met-enkephalin release from synaptosomes. Clues to the locus of action. J. Biol. Chem. 267, 21338-21343.

Meng, J., Dolly, J. O., and Wang, J. (2014). Selective cleavage of SNAREs in sensory neurons unveils protein complexes mediating peptide exocytosis triggered by different stimuli. Mol. Neurobiol. 50, 574-588. doi: 10.1007/s12035-014-8665-1

Meng, J., Ovsepian, S. V., Wang, J., Pickering, M., Sasse, A., Aoki, K. R., et al. (2009). Activation of TRPV1 mediates calcitonin gene-related peptide release, which excites trigeminal sensory neurons and is attenuated by a retargeted botulinum toxin with anti-nociceptive potential. J. Neurosci. 29, 4981-4992. doi: 10.1523/JNEUROSCI.5490-08.2009

Meng, J., Wang, J., Steinhoff, M., and Dolly, J. O. (2016). TNFalpha induces co-trafficking of TRPV1/TRPA1 in VAMP1-containing vesicles to the plasmalemma via Munc18-1/syntaxin1/SNAP-25 mediated fusion. Sci. Rep. 6:21226. doi: $10.1038 /$ srep21226

Michael, G. J., and Priestley, J. V. (1999). Differential expression of the mRNA for the vanilloid receptor subtype 1 in cells of the adult rat dorsal root and nodose ganglia and its downregulation by axotomy. J. Neurosci. 19, 1844-1854.

Mohanty, S., Dhawan, B., and Chaudhry, R. (2001). Botulism: an update. Indian J. Med. Microbiol. 19, 35-43.

Morenilla-Palao, C., Planells-Cases, R., Garcia-Sanz, N., and Ferrer-Montiel, A. (2004). Regulated exocytosis contributes to protein kinase C potentiation of vanilloid receptor activity. J. Biol. Chem. 279, 25665-25672. doi: 10.1074/jbc. M311515200
Muraro, L., Tosatto, S., Motterlini, L., Rossetto, O., and Montecucco, C. (2009). The N-terminal half of the receptor domain of botulinum neurotoxin A binds to microdomains of the plasma membrane. Biochem. Biophys. Res. Commun. 380, 76-80. doi: 10.1016/j.bbrc.2009.01.037

Nakov, R., Habermann, E., Hertting, G., Wurster, S., and Allgaier, C. (1989). Effects of botulinum A toxin on presynaptic modulation of evoked transmitter release. Eur. J. Pharmacol. 164, 45-53. doi: 10.1016/0014-2999(89)90229-x

Naumann, M., and Jankovic, J. (2004). Safety of botulinum toxin type A: a systematic review and meta-analysis. Curr. Med. Res. Opin. 20, 981-990. doi: 10.1185/030079904125003962

Nugent, M., Yusef, Y. R., Meng, J., Wang, J., and Dolly, J. O. (2018). A SNAP-25 cleaving chimera of botulinum neurotoxin /A and /E prevents TNFalphainduced elevation of the activities of native TRP channels on early postnatal rat dorsal root ganglion neurons. Neuropharmacology 138, 257-266. doi: 10.1016/ j.neuropharm.2018.06.016

Numazaki, M., Tominaga, T., Takeuchi, K., Murayama, N., Toyooka, H., and Tominaga, M. (2003). Structural determinant of TRPV1 desensitization interacts with calmodulin. Proc. Natl. Acad. Sci. U. S. A. 100, 8002-8006. doi: 10.1073/pnas. 1337252100

Numazaki, M., Tominaga, T., Toyooka, H., and Tominaga, M. (2002). Direct phosphorylation of capsaicin receptor VR1 by protein kinase Cepsilon and identification of two target serine residues. J. Biol. Chem. 277, 13375-13378. doi: $10.1074 /$ jbc.C200104200

Obata, K., Katsura, H., Mizushima, T., Yamanaka, H., Kobayashi, K., Dai, Y., et al. (2005). TRPA1 induced in sensory neurons contributes to cold hyperalgesia after inflammation and nerve injury. J. Clin. Invest. 115, 2393-2401. doi: 10. $1172 /$ JCI25437

O’Neill, J., Brock, C., Olesen, A. E., Andresen, T., Nilsson, M., and Dickenson, A. H. (2012). Unravelling the mystery of capsaicin: a tool to understand and treat pain. Pharmacol. Rev. 64, 939-971. doi: 10.1124/pr.112.006163

Pan, P. Y., Tian, J. H., and Sheng, Z. H. (2009). Snapin facilitates the synchronization of synaptic vesicle fusion. Neuron 61, 412-424. doi: 10.1016/ j.neuron.2008.12.029

Park, H. J., Lee, Y., Lee, J., Park, C., and Moon, D. E. (2006). The effects of botulinum toxin A on mechanical and cold allodynia in a rat model of neuropathic pain. Can. J. Anaesth. 53, 470-477. doi: 10.1007/BF03022619

Patapoutian, A., Tate, S., and Woolf, C. J. (2009). Transient receptor potential channels: targeting pain at the source. Nat. Rev. Drug Discov. 8, 55-68. doi: $10.1038 / \mathrm{nrd} 2757$

Paterson, K., Lolignier, S., Wood, J. N., McMahon, S. B., and Bennett, D. L. (2014). Botulinum toxin-A treatment reduces human mechanical pain sensitivity and mechanotransduction. Ann. Neurol. 75, 591-596. doi: 10.1002/ana.24122

Pirazzini, M., Rossetto, O., Eleopra, R., and Montecucco, C. (2017). Botulinum neurotoxins: biology, pharmacology, and toxicology. Pharmacol. Rev. 69, 200235. doi: $10.1124 /$ pr.116.012658

Premkumar, L. S., and Ahern, G. P. (2000). Induction of vanilloid receptor channel activity by protein kinase C. Nature 408, 985-990. doi: 10.1038/35050121

Prescott, E. D., and Julius, D. (2003). A modular PIP2 binding site as a determinant of capsaicin receptor sensitivity. Science 300, 1284-1288. doi: 10.1126/science. 1083646

Raisinghani, M., Zhong, L., Jeffry, J. A., Bishnoi, M., Pabbidi, R. M., Pimentel, F., et al. (2011). Activation characteristics of transient receptor potential ankyrin 1 and its role in nociception. Am. J. Physiol. Cell Physiol. 301, C587-C600. doi: 10.1152/ajpcell.00465.2010

Reichling, D. B., and Levine, J. D. (2009). Critical role of nociceptor plasticity in chronic pain. Trends Neurosci. 32, 611-618. doi: 10.1016/j.tins.2009.07.007

Roche, N., Schnitzler, A., Genet, F. F., Durand, M. C., and Bensmail, D. (2008). Undesirable distant effects following botulinum toxin type a injection. Clin. Neuropharmacol. 31, 272-280. doi: 10.1097/WNF.0b013e31815cba8a

Rosenbaum, T., and Simon, S. A. (2007). "TRPV1 receptors and signal transduction," in TRP Ion Channel Function in Sensory Transduction and Cellular Signaling Cascades, eds W. B. Liedtke and S. Heller (Boca Raton (FL): CRC Press).

Schiavo, G., Matteoli, M., and Montecucco, C. (2000). Neurotoxins affecting neuroexocytosis. Physiol. Rev. 80, 717-766. doi: 10.1152/physrev.2000.80.2.717

Scholz, J., and Woolf, C. J. (2002). Can we conquer pain? Nat. Neurosci. 5(Suppl.), 1062-1067. doi: 10.1038/nn942 
Sexton, J. E., Vernon, J., and Wood, J. N. (2014). TRPs and pain. Handb. Exp. Pharmacol. 223, 873-897. doi: 10.1007/978-3-319-05161-1_6

Shimizu, T., Shibata, M., Toriumi, H., Iwashita, T., Funakubo, M., Sato, H., et al. (2012). Reduction of TRPV1 expression in the trigeminal system by botulinum neurotoxin type-A. Neurobiol. Dis. 48, 367-378. doi: 10.1016/j.nbd.2012.07.010

Simpson, L. L. (1981). The origin, structure, and pharmacological activity of botulinum toxin. Pharmacol. Rev. 33, 155-188.

Spicarova, D., Nerandzic, V., and Palecek, J. (2011). Modulation of spinal cord synaptic activity by tumor necrosis factor alpha in a model of peripheral neuropathy. J. Neuroinflammation 8:177. doi: 10.1186/1742-2094-8-177

Stephan, F., Habre, M., and Tomb, R. (2014). Clinical resistance to three types of botulinum toxin type A in aesthetic medicine. J. Cosmet. Dermatol. 13, 346-348. doi: 10.1111 /jocd. 12108

Sudhof, T. C., and Rothman, J. E. (2009). Membrane fusion: grappling with SNARE and SM proteins. Science 323, 474-477. doi: 10.1126/science.1161748

Tang, J., Maximov, A., Shin, O. H., Dai, H., Rizo, J., and Sudhof, T. C. (2006). A complexin/synaptotagmin 1 switch controls fast synaptic vesicle exocytosis. Cell 126, 1175-1187. doi: 10.1016/j.cell.2006.08.030

Treede, R. D., Meyer, R. A., Raja, S. N., and Campbell, J. N. (1992). Peripheral and central mechanisms of cutaneous hyperalgesia. Prog. Neurobiol. 38, 397-421. doi: 10.1016/0301-0082(92)90027-c

Treede, R. D., Rief, W., Barke, A., Aziz, Q., Bennett, M. I., Benoliel, R., et al. (2015). A classification of chronic pain for ICD-11. Pain 156, 1003-1007. doi: 10.1097/j.pain.0000000000000160

Truong, D. D., Stenner, A., and Reichel, G. (2009). Current clinical applications of botulinum toxin. Curr. Pharm. Des. 15, 3671-3680. doi: 10.2174/ 138161209789271843

Tugnoli, V., Capone, J. G., Eleopra, R., Quatrale, R., Sensi, M., Gastaldo, E., et al. (2007). Botulinum toxin type A reduces capsaicin-evoked pain and neurogenic vasodilatation in human skin. Pain 130, 76-83. doi: 10.1016/j.pain.2006.10.030

Vellani, V., Mapplebeck, S., Moriondo, A., Davis, J. B., and McNaughton, P. A. (2001). Protein kinase $C$ activation potentiates gating of the vanilloid receptor VR1 by capsaicin, protons, heat and anandamide. J. Physiol. 534(Pt 3), 813-825. doi: 10.1111/j.1469-7793.2001.00813.x

Wang, J., Casals-Diaz, L., Zurawski, T., Meng, J., Moriarty, O., Nealon, J., et al. (2017). A novel therapeutic with two SNAP-25 inactivating proteases shows long-lasting anti-hyperalgesic activity in a rat model of neuropathic pain. Neuropharmacology 118, 223-232. doi: 10.1016/j.neuropharm.2017.03.026

Wang, J., Zurawski, T. H., Meng, J., Lawrence, G., Olango, W. M., Finn, D. P., et al. (2011). A dileucine in the protease of botulinum toxin A underlies its long-lived neuroparalysis: transfer of longevity to a novel potential therapeutic. J. Biol. Chem. 286, 6375-6385. doi: 10.1074/jbc.M110.181784
Weiss, R. A., and Lavin, P. T. (2009). Reduction of pain and anxiety prior to botulinum toxin injections with a new topical anesthetic method. Ophthalmic Plast. Reconstr. Surg. 25, 173-177. doi: 10.1097/IOP.0b013e3181a1 $45 \mathrm{ca}$

Wollina, U., and Konrad, H. (2005). Managing adverse events associated with botulinum toxin type A: a focus on cosmetic procedures. Am. J. Clin. Dermatol. 6, 141-150. doi: 10.2165/00128071-200506030-00001

Wyndaele, J., and Van Dromme, S. (2002). Muscular weakness as side effect of botulinum toxin injection for neurogenic detrusor overactivity. Spinal Cord 40, 599-600.

Xiao, L., Cheng, J., Zhuang, Y., Qu, W., Muir, J., Liang, H., et al. (2013). Botulinum toxin type A reduces hyperalgesia and TRPV1 expression in rats with neuropathic pain. Pain Med. 14, 276-286. doi: 10.1111/pme.12017

Yiangou, Y., Anand, U., Otto, W. R., Sinisi, M., Fox, M., Birch, R., et al. (2011). Increased levels of SV2A botulinum neurotoxin receptor in clinical sensory disorders and functional effects of botulinum toxins $\mathrm{A}$ and $\mathrm{E}$ in cultured human sensory neurons. J. Pain Res. 4, 347-355. doi: 10.2147/JPR.S2 5189

Zhang, X., Huang, J., and McNaughton, P. A. (2005). NGF rapidly increases membrane expression of TRPV1 heat-gated ion channels. EMBO J. 24, 42114223. doi: 10.1038/sj.emboj.7600893

Zuber, M., Sebald, M., Bathien, N., de Recondo, J., and Rondot, P. (1993). Botulinum antibodies in dystonic patients treated with type A botulinum toxin: frequency and significance. Neurology 43, 1715-1718. doi: 10.1212/wnl.43.9. 1715

Conflict of Interest: The authors declare that the research was conducted in the absence of any commercial or financial relationships that could be construed as a potential conflict of interest.

Publisher's Note: All claims expressed in this article are solely those of the authors and do not necessarily represent those of their affiliated organizations, or those of the publisher, the editors and the reviewers. Any product that may be evaluated in this article, or claim that may be made by its manufacturer, is not guaranteed or endorsed by the publisher.

Copyright (c) 2021 Go, Ji, Kim, Berta and Park. This is an open-access article distributed under the terms of the Creative Commons Attribution License (CC BY). The use, distribution or reproduction in other forums is permitted, provided the original author(s) and the copyright owner(s) are credited and that the original publication in this journal is cited, in accordance with accepted academic practice. No use, distribution or reproduction is permitted which does not comply with these terms. 